\title{
Associations between Bethesda categories and tumor characteristics of conventional papillary thyroid carcinoma
}

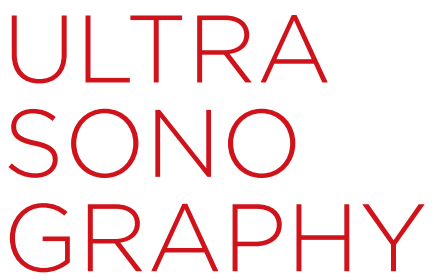

\author{
Vivian Youngjean Park, Eun-Kyung Kim, Jin Young Kwak, Jung Hyun Yoon, \\ Hee Jung Moon
}

Department of Radiology and Research Institute of Radiological Science, Severance Hospital, Yonsei University College of Medicine, Seoul, Korea

\section{ORIGINAL ARTICLE}

https://doi.org/10.14366/usg. 17053 pISSN: 2288-5919 - elSSN: 2288-5943 Ultrasonography 2018;37:323-329

Purpose: The aim of this study was to investigate the associations of Bethesda categories III, $\mathrm{V}$, and VI with the clinical and pathological features of thyroid nodules surgically confirmed as conventional papillary thyroid carcinomas (PTCs).

Methods: We analyzed 1,990 consecutive patients diagnosed with conventional PTC at surgery with preoperative Bethesda categories III, V, or VI. We determined the odds ratio (ORs) of the clinical and pathological variables associated with categories III and V, using category VI as the reference.

Results: Category III and V PTCs had a smaller pathological tumor size (OR, 0.934 and OR, 0.969 , respectively) and less frequently had central lymph node metastasis (OR, 0.487 and $O R$, 0.780 , respectively) than category VI PTCs. Category III PTCs less frequently showed suspicious ultrasonographic features $(O R, 0.296)$ than category VI PTCs, and category V PTCs less frequently had gross extrathyroidal extension, with borderline significance $(O R, 0.643 ; P=0.059)$.

Conclusion: Conventional PTCs with a preoperative Bethesda category of III or V may less frequently exhibit poor prognostic factors than those with malignant cytology.

Keywords: Thyroid nodule; Biopsy, fine-needle; Thyroid cancer, papillary; Ultrasonography

\section{Introduction}

The Bethesda System for Reporting Thyroid Cytopathology has been widely adopted following its proposal at a State-of-the-Science Conference in 2007, and has served as the primary method of interpreting thyroid fine-needle aspiration (FNA). It provides a 6-tiered standardized system with associated implied risks of malignancy for each diagnostic category [1]. Whereas thyroid nodules assigned to the Bethesda category VI (malignant) show cytomorphologic features conclusive for malignancy and have an implied risk of malignancy of $97 \%-99 \%$, thyroid nodules assigned classified as Bethesda categories III (atypia of undetermined significance or follicular lesion of undetermined significance [AUS/FLUS]) and V (suspicious for malignancy) show cytomorphologic features inconclusive for malignancy, with implied risks of malignancy of $5 \%-15 \%$ and $60 \%-70 \%$, respectively [1].

In addition to its original role as a diagnostic tool, recent research has reported possible

Received: July 31, 2017

Revised: November 20, 2017

Accepted: November 22, 2017

Correspondence to:

Hee Jung Moon, MD, PhD, Department of Radiology and Research Institute of Radiological Science, Severance Hospital, Yonsei University College of Medicine, 50 Yonsei-ro, Seodaemungu, Seoul 03722, Korea

Tel. $+82-2-2228-7400$

Fax. +82-2-393-3035

E-mail: artemis4u@yuhs.ac

This is an Open Access article distributed under the terms of the Creative Commons Attribution NonCommercial License (http://creativecommons.org/ licenses/by-nc/3.0/) which permits unrestricted noncommercial use, distribution, and reproduction in any medium, provided the original work is properly cited.

Copyright () 2018 Korean Society of Ultrasound in Medicine (KSUM)

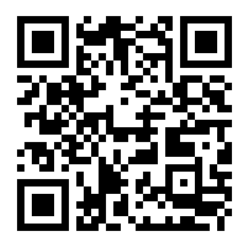

How to cite this article:

Park VY, Kim EK, Kwak JY, Yoon JH, Moon HJ. Associations between Bethesda categories and tumor characteristics of conventional papillary thyroid carcinoma. Ultrasonography. 2018 0ct;37(4):323-329. 
associations between Bethesda categories and pathological tumor characteristics [2-4]. Higher Bethesda categories at FNA have been associated with a larger pathological size, N stage, lymphovascular invasion, extrathyroidal extension, and aggressive variants of papillary thyroid carcinoma (PTC) [2-4]. However, the populations and methods have varied considerably across studies, including various histologic types of both thyroid malignancies and PTC and differing in whether Bethesda categories $\mathrm{V}$ and $\mathrm{VI}$ were combined [2-4]. Furthermore, the risks of poor pathological factors differ across histologic subtypes, and a previous study reported that there were no differences in pathologic features according to Bethesda categories when comparing PTCs of the same histologic subtype [3].

Therefore, the purpose of this study was to investigate the associations of Bethesda categories III, V, and VI with the clinical and pathological features of thyroid nodules surgically confirmed as conventional PTCs.

\section{Materials and Methods}

\section{Study Population}

Our institutional review board approved this retrospective study, and the requirement for informed consent was waived. From March 2014 to October 2015, 2,173 consecutive patients underwent preoperative ultrasonography (US) and were confirmed to have conventional PTC at our institution. Among them, 80 patients with coexisting multiple tumors of other histologic subtypes were excluded. All the remaining 2,093 patients underwent US-FNA $(n=2,018)$ or core biopsy $(n=75)$ prior to surgery. Among the 2,018 patients who underwent US-FNA, 1,990 had a Bethesda category III $(n=98,4.9 \%), V(n=730,36.7 \%)$, or VI $(n=1,162,58.4 \%)$ lesion on preoperative US-FNA, which was performed either at our institution ( $n=335)$ or at an outside clinic $(n=1,655)$. FNA slides that were performed at outside clinics were reviewed by the pathology department of our institution. These 1,990 patients (mean age, 44.1 years; range, 10 to 79 years) constituted our study population. Of the 1,990 patients, 1,564 were women (mean age, 43.9 years; range, 10 to 79 years) and 426 were men (mean age, 44.7 years; range, 19 to 77 years). The median pathological tumor size was 9.6 $\mathrm{mm}$ (range, 1 to $130 \mathrm{~mm}$ ).

\section{US, US-FNA, and Cytological Diagnoses}

At our institution, preoperative US for staging is routinely performed on patients for whom thyroid surgery is planned. US was performed by one of 15 board-certified radiologists with 1-20 years of experience in thyroid imaging, using a 5- to 12MHz linear probe (EPIQ5 or iU22, Philips Medical Systems, Bothell, WA, USA). The US features and US assessment of thyroid nodules were prospectively recorded at the time of preoperative US. The internal components were classified as solid, predominantly solid ( $>50 \%$ solid for a mixed nodule), or predominantly cystic ( $>50 \%$ cystic for a mixed nodule). Echogenicity was classified as hyperechogenicity, isoechogenicity, hypoechogenicity, or marked hypoechogenicity [5]. Margins were classified as well-circumscribed, microlobulated, or irregular. Calcifications were categorized as microcalcifications, macrocalcifications, or no calcifications. Shape was classified as taller-than-wide (greater in its anteroposterior dimension than in its transverse dimension) or wider-than-tall. The US features that were considered suspicious for malignancy included marked hypoechogenicity, microlobulated or irregular margins, microcalcifications, and a taller-than-wide shape. Thyroid nodules that showed at least one of the above suspicious US features were assessed as suspicious, and nodules without suspicious US features were assessed as probably benign.

The Bethesda classification has been used at our institution since December 2009. Bethesda category VI is assigned whenever the cytomorphologic features are conclusive for malignancy [1]. Bethesda category $V$ is assigned if only 1-2 characteristic features of PTC are present, if they are only focal and not widespread throughout the follicular cell population, or if the sample is sparsely cellular [1]. Bethesda category III is assigned when thyroid FNAs cannot be easily classified as benign, suspicious, or malignant [1]. During the study period, the cytological diagnosis was performed by one of five pathologists with at least 4 years of experience in thyroid cytopathology, who was arbitrarily assigned according to the hospital schedule.

\section{Surgical Procedure and Pathology}

Total or near-total thyroidectomy was performed in patients with multiple tumors, extrathyroidal invasion, or lymph node metastasis (LNM) upon preoperative evaluation or intraoperative findings. Central compartment neck dissection including the paratracheal, pretracheal, and prelaryngeal lymph nodes was routinely performed in all patients. Bilateral central compartment neck dissection was performed in patients who underwent total or near-total thyroidectomy and ipsilateral central compartment neck dissection was performed in patients who underwent hemithyroidectomy. Lateral compartment neck dissection was selectively performed in patients diagnosed with lateral LNM on preoperative US-FNA. If suspicious lymph nodes were found at the time of surgery, an intraoperative frozen biopsy was performed. In patients confirmed to have lateral LNM, the lateral neck compartments including levels 2, 3, 4, and anterior 5 were dissected. Of the 1,990 patients with conventional PTC, 1,073 (53.9\%) underwent total or near-total thyroidectomy and 917 (46.1\%) underwent hemithyroidectomy. One 
hundred and ninety-six patients (9.8\%) underwent therapeutic lateral compartment neck dissection. We evaluated the pathological tumor size, multiplicity including both unilateral and bilateral tumor foci, and the presence of central and lateral LNM based on final surgical pathology reports. According to the eighth edition of the American Joint Committee on Cancer (AJCC) staging system [6], gross extrathyroidal extension was defined as extension involving major structures (strap muscles, subcutaneous soft tissue, larynx, trachea, esophagus, recurrent laryngeal nerve, prevertebral fascia, carotid artery, or mediastinal vessels) documented in the operative report.

\section{Statistical Analysis}

Clinical and pathological variables and US assessments were compared among Bethesda categories III, V, and VI using the chisquare test for categorical variables and the analysis of variance test for continuous variables. Post hoc pairwise analysis was performed with the Bonferroni method for multiple comparison adjustment. To assess the associations between Bethesda categories and clinical variables, pathological variables, and US assessments, multinomial logistic regression analysis was carried out using Bethesda category $\mathrm{VI}$ as the reference. Variables that had a P-value of $<0.05$ in the univariate multinomial logistic regression analysis were included in a multivariable multinomial logistic regression model to assess whether they had independent associations with the Bethesda categories. The statistical analysis was performed using SAS ver. 9.4 (SAS Inc., Cary, NC, USA) and SPSS ver. 23.0 (IBM Corp., Armonk, NY, USA).

\section{Results}

Of the 1,990 patients with conventional PTC, $127(6.4 \%)$ had gross

Table 1. Comparison of clinical and pathologic characteristics among Bethesda categories III, V, and VI in 1,990 patients with conventional papillary thyroid carcinoma

\begin{tabular}{|c|c|c|c|c|c|c|c|}
\hline \multirow{2}{*}{ Variable } & \multicolumn{3}{|c|}{ Bethesda classification } & \multirow{2}{*}{$\begin{array}{l}\text { Overall } \\
\text { P-value }\end{array}$} & \multicolumn{3}{|c|}{$\begin{array}{l}\text { Post hoc pairwise P-values with } \\
\text { Bonferroni correction }\end{array}$} \\
\hline & $\begin{array}{l}\text { Category III (1) } \\
(\mathrm{n}=98)\end{array}$ & $\begin{array}{l}\text { Category V (2) } \\
\quad(n=730)\end{array}$ & $\begin{array}{l}\text { Category VI (3) } \\
(n=1,162)\end{array}$ & & (1) vs. (2) & (1) vs. (3) & (2) vs. (3) \\
\hline Age (yr) & $46.5 \pm 12.7$ & $44.0 \pm 11.7$ & $43.9 \pm 12.0$ & 0.118 & & & \\
\hline Sex & & & & 0.371 & $>0.999$ & $>0.999$ & $>0.999$ \\
\hline Male & $72(73.5)$ & $581(79.6)$ & $911(78.4)$ & & & & \\
\hline Female & $26(26.5)$ & $149(20.4)$ & $251(21.6)$ & & & & \\
\hline US assessment & & & & 0.019 & 0.114 & 0.028 & $>0.999$ \\
\hline Suspicious & $91(92.9)$ & $709(97.1)$ & $1,137(97.8)$ & & & & \\
\hline Probably benign & $7(7.1)$ & $21(2.9)$ & $25(2.2)$ & & & & \\
\hline Tumor size $(\mathrm{mm})$ & $7.6 \pm 5.1$ & $8.6 \pm 6.1$ & $10.4 \pm 8.0$ & $<0.001^{\text {c) }}$ & & & \\
\hline Gross extrathyroidal extension & & & & $<0.001$ & $>0.999$ & 0.057 & $<0.001$ \\
\hline Yes & $2(2.0)$ & $28(3.8)$ & $97(8.3)$ & & & & \\
\hline No & $96(98.0)$ & $702(96.2)$ & $1,065(91.7)$ & & & & \\
\hline Central lymph node metastasis & & & & $<0.001$ & 0.131 & $<0.001$ & $<0.001$ \\
\hline Yes & $23(23.5)$ & $250(34.2)$ & $511(44.0)$ & & & & \\
\hline No & $75(76.5)$ & $480(65.8)$ & $651(56.0)$ & & & & \\
\hline Lateral lymph node metastasis & & & & 0.003 & $>0.999$ & 0.664 & 0.004 \\
\hline Yes & $7(7.1)$ & $52(7.1)$ & $137(11.8)$ & & & & \\
\hline No & $91(92.9)$ & $678(92.9)$ & $1,025(88.2)$ & & & & \\
\hline Multiplicity & & & & 0.103 & $>0.999$ & $>0.999$ & 0.138 \\
\hline Yes & 29 (29.6) & $217(29.7)$ & $398(34.3)$ & & & & \\
\hline No & 69 (70.4) & $513(70.3)$ & $764(65.7)$ & & & & \\
\hline
\end{tabular}

Values are presented as mean \pm standard deviation or number (\%).

US, ultrasonography; ANOVA, analysis of variance.

${ }^{\text {a) }}$ Calculated using the chi-square test or the Fisher exact test for categorical variables and ANOVA for continuous variables. ${ }^{\text {b) }}$ Calculated using the chi-square test or the Fisher exact test for categorical variables and the $t$ test for continuous variables. The post hoc pairwise P-values with the Bonferroni correction were calculated by multiplying the pairwise raw P-values by 3, which is the number of comparisons made. "Significant differences were seen between categories III and VI and between categories $\mathrm{V}$ and VI, using ANOVA with Bonferroni post hoc analysis. 
extrathyroidal extension, 784 (39.4\%) had central LNM, 196 (9.8\%) had lateral LNM, and $644(32.4 \%)$ had multiple tumors. Category VI PTCs had a higher proportion of nodules with suspicious US features than category III PTCS, a larger pathological tumor size, a higher proportion of nodules with gross extrathyroidal extension and central LNM than category III and category V PTCs, and a higher proportion of lateral LNM than category V PTCs (Table 1).

In the univariate multinomial logistic regression analysis, patients with category III PTCs were older than those with category VI PTCS (odds ratio $[O R], 1.018 ; 95 \%$ confidence interval $[\mathrm{Cl}], 1.001$ to 1.035). Both category III PTCs and category V PTCs had a smaller pathological tumor size, less frequently had central LNM, and less frequently had gross extrathyroidal extension than category VI PTCS (Table 2). Category III PTCs less frequently showed suspicious US features (OR, $0.286 ; 95 \% \mathrm{Cl}, 0.120$ to 0.679$)$ and category V PTCs less frequently had lateral $\mathrm{LNM}(\mathrm{OR}, 0.574 ; 95 \% \mathrm{Cl}, 0.411$ to 0.801$)$ and multiple tumors $(\mathrm{OR}, 0.812 ; 95 \% \mathrm{Cl}, 0.665$ to 0.991$)$ than category VI PTCs (Figs. 1, 2).

In the multivariable multinomial logistic regression analysis, category III and category V PTCs had a smaller pathological tumor size (category III: OR, $0.934 ; 95 \% \mathrm{Cl}, 0.889$ to 0.981 ; category V: $\mathrm{OR}, 0.969 ; 95 \% \mathrm{Cl}, 0.952$ to 0.986$)$ and less frequently had central LNM (category III: OR, $0.487 ; 95 \% \mathrm{Cl}, 0.287$ to 0.827 ; category V: OR, $0.780 ; 95 \% \mathrm{Cl}, 0.633$ to 0.962 ) than category VI PTCs (Table 2). Category III PTCs less frequently showed suspicious US features (OR, $0.296 ; 95 \% \mathrm{Cl}, 0.121$ to 0.720 ) than category VI PTCs. Lateral LNM and gross extrathyroidal extension were not significantly associated with Bethesda categories in the multivariable analysis, although

Table 2. Univariate and multivariable multinomial logistic regression analysis of 1,990 conventional papillary thyroid carcinomas using category $\mathrm{VI}$ as the reference

\begin{tabular}{|c|c|c|c|c|c|c|c|c|}
\hline \multirow[b]{2}{*}{ Variable } & \multicolumn{4}{|c|}{ Univariate multinomial } & \multicolumn{4}{|c|}{ Multivariable multinomial } \\
\hline & $\begin{array}{l}\text { Category III } \\
\quad(n=98) \\
\text { OR }(95 \% \mathrm{Cl})\end{array}$ & P-value & $\begin{array}{c}\text { Category V } \\
(n=730) \\
\text { OR }(95 \% \mathrm{Cl})\end{array}$ & P-value & $\begin{array}{l}\text { Category III } \\
\quad(n=98) \\
\text { OR }(95 \% \mathrm{Cl})\end{array}$ & P-value & $\begin{array}{c}\text { Category V } \\
(n=730) \\
\text { OR }(95 \% \mathrm{Cl})\end{array}$ & P-value \\
\hline Sex & & 0.259 & & 0.537 & & 0.118 & & 0.902 \\
\hline Female & 1 (Ref.) & & 1 (Ref.) & & 1 (Ref.) & & 1 (Ref.) & \\
\hline US assessment & & 0.005 & & 0.320 & & 0.007 & & 0.312 \\
\hline Suspicious & $\begin{array}{c}0.286 \\
(0.120-0.679)\end{array}$ & & $\begin{array}{c}0.742 \\
(0.412-1.336)\end{array}$ & & $\begin{array}{c}0.296 \\
(0.121-0.720)\end{array}$ & & $\begin{array}{c}0.734 \\
(0.403-1.336)\end{array}$ & \\
\hline Probably benign & 1 (Ref.) & & 1 (Ref.) & & 1 (Ref.) & & 1 (Ref.) & \\
\hline Yes & $\begin{array}{c}0.229 \\
(0.056-0.943)\end{array}$ & & $\begin{array}{c}0.438 \\
(0.285-0.674)\end{array}$ & & $\begin{array}{c}0.432 \\
(0.100-1.869)\end{array}$ & & $\begin{array}{c}0.643 \\
(0.406-1.017)\end{array}$ & \\
\hline No & 1 (Ref.) & & 1 (Ref.) & & 1 (Ref.) & & 1 (Ref.) & \\
\hline Central LNM & & $<0.001$ & & $<0.001$ & & 0.008 & & 0.020 \\
\hline Yes & $\begin{array}{c}0.391 \\
(0.241-0.632)\end{array}$ & & $\begin{array}{c}0.664 \\
(0.548-0.804)\end{array}$ & & $\begin{array}{c}0.487 \\
(0.287-0.827)\end{array}$ & & $\begin{array}{c}0.780 \\
(0.633-0.962)\end{array}$ & \\
\hline No & 1 (Ref.) & & 1 (Ref.) & & 1 (Ref.) & & 1 (Ref.) & \\
\hline Lateral LNM & & 0.170 & & 0.001 & & 0.468 & & 0.456 \\
\hline Yes & $\begin{array}{c}0.576 \\
(0.261-1.267)\end{array}$ & & $\begin{array}{c}0.574 \\
(0.411-0.801)\end{array}$ & & $\begin{array}{c}1.383 \\
(0.577-3.312)\end{array}$ & & $\begin{array}{c}0.870 \\
(0.603-1.255)\end{array}$ & \\
\hline Multiplicity & & 0.350 & & 0.041 & & 0.785 & & 0.375 \\
\hline Yes & $\begin{array}{c}0.807 \\
(0.514-1.266)\end{array}$ & & $\begin{array}{c}0.812 \\
(0.665-0.991)\end{array}$ & & $\begin{array}{c}0.937 \\
(0.588-1.494)\end{array}$ & & $\begin{array}{c}0.911 \\
(0.741-1.120)\end{array}$ & \\
\hline No & 1 (Ref.) & & 1 (Ref.) & & 1 (Ref.) & & 1 (Ref.) & \\
\hline
\end{tabular}

OR, odds ratio; $\mathrm{Cl}$, confidence interval; US, ultrasonography; ETE, extrathyroidal extension; LNM, lymph node metastasis; Ref., Reference. 
category V PTCs less frequently had gross extrathyroidal extension, with borderline significance $(O R, 0.643 ; 95 \% \mathrm{Cl}, 0.406$ to 1.017 ; $\mathrm{P}=0.059$ ) (Fig. 3).

\section{Discussion}

We aimed to investigate the associations of Bethesda categories with the clinical and pathological features of conventional PTCS, using category VI as the reference. Compared with category VI PTCS, both category III and V PTCs had a smaller pathological tumor size and less frequently had central LNM. In addition, category III PTCS less frequently showed suspicious US features, and category V PTCs less frequently had gross extrathyroidal extension than category $\mathrm{VI}$ PTCs, with borderline significance $(P=0.059)$. Our results show that the preoperative Bethesda categories provided valuable information regarding the pathological features of conventional PTC.

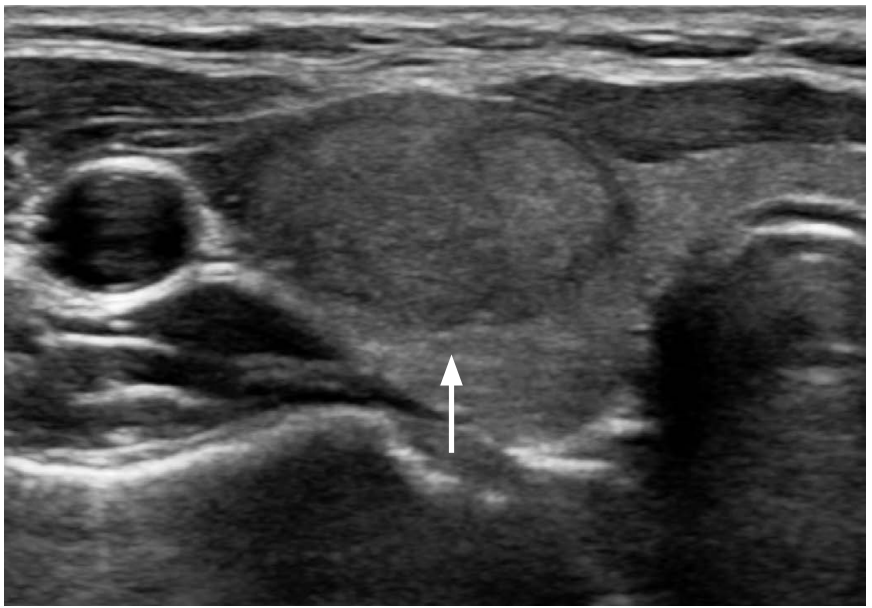

A

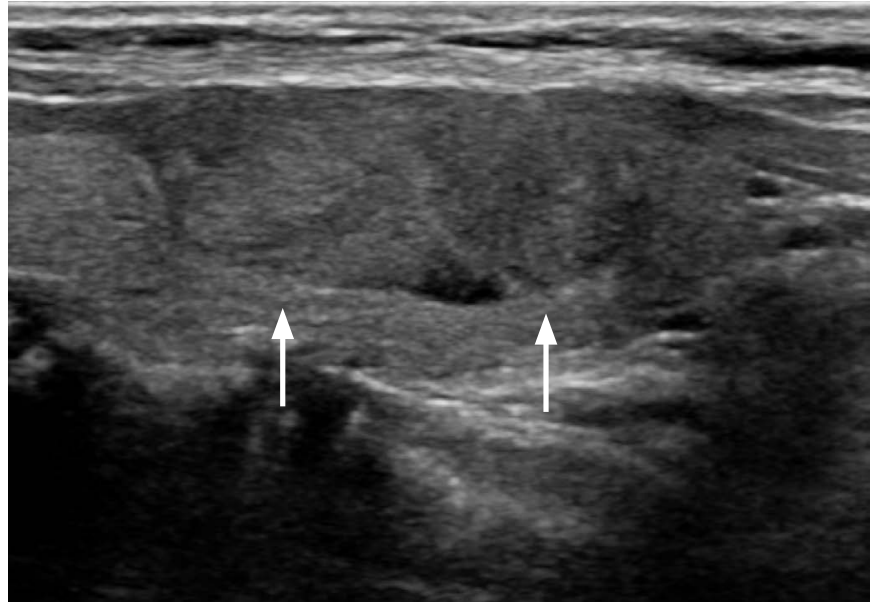

B

Fig. 1. A 32-year-old woman with conventional papillary thyroid carcinoma that was initially diagnosed as Bethesda category III (atypia of undetermined significance or follicular lesion of undetermined significance) by fine-needle aspiration.

A, B. Ultrasonography ( $A$, transverse; B, longitudinal view) shows an isoechoic solid mass in the right thyroid gland with no suspicious ultrasonographic features (arrows). The pathologic tumor size was $16 \mathrm{~mm}$, and there was no evidence of lymph node metastasis or gross extrathyroidal extension at surgery.

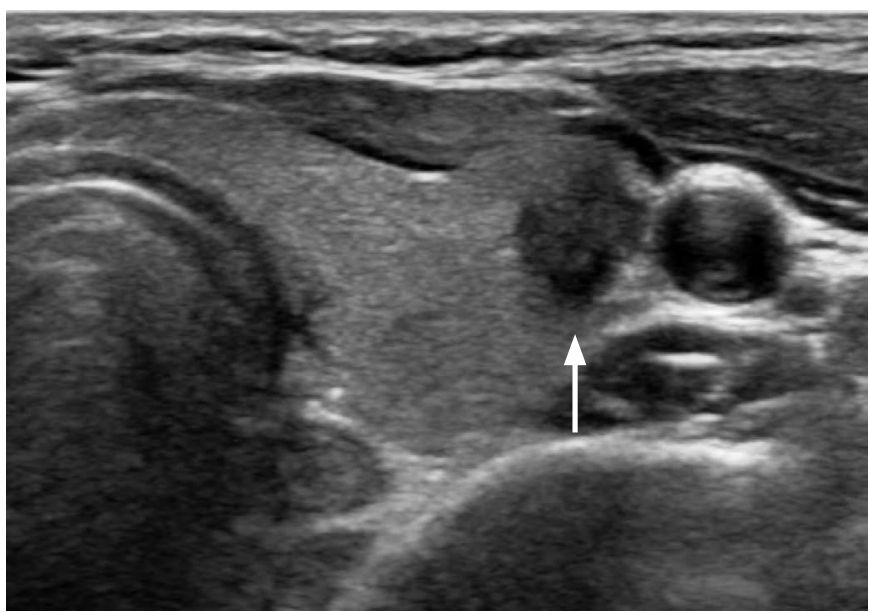

A

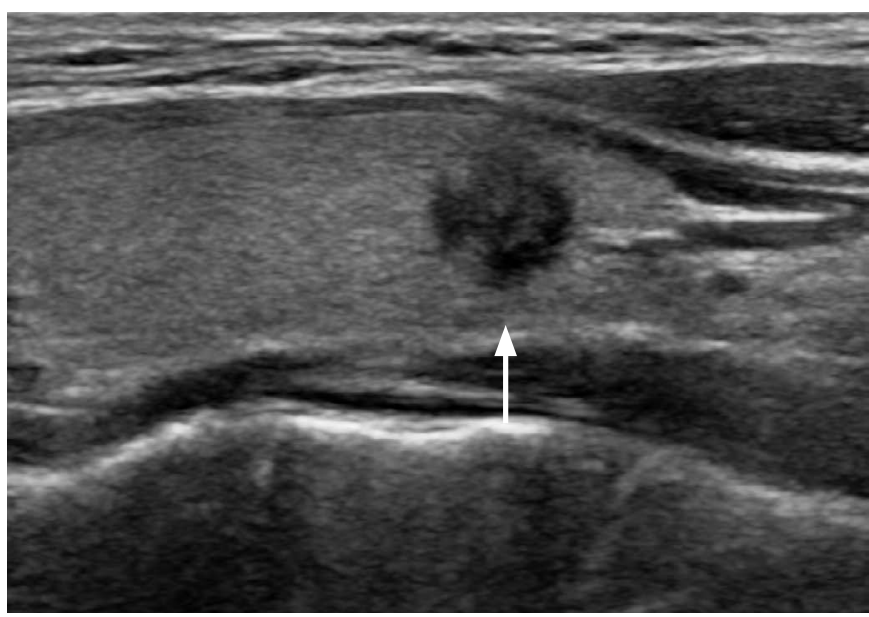

B

Fig. 2. A 46-year-old woman with conventional papillary thyroid carcinoma that was initially diagnosed as Bethesda category $\mathrm{V}$ (suspicious for malignancy) by fine-needle aspiration.

A, B. Ultrasonography (A, transverse; B, longitudinal view) shows a hypoechoic, irregular, non-parallel mass with spiculated margins in the left thyroid gland (arrows). The pathologic tumor size was $10 \mathrm{~mm}$, and there was no evidence of lymph node metastasis or gross extrathyroidal extension at surgery. 


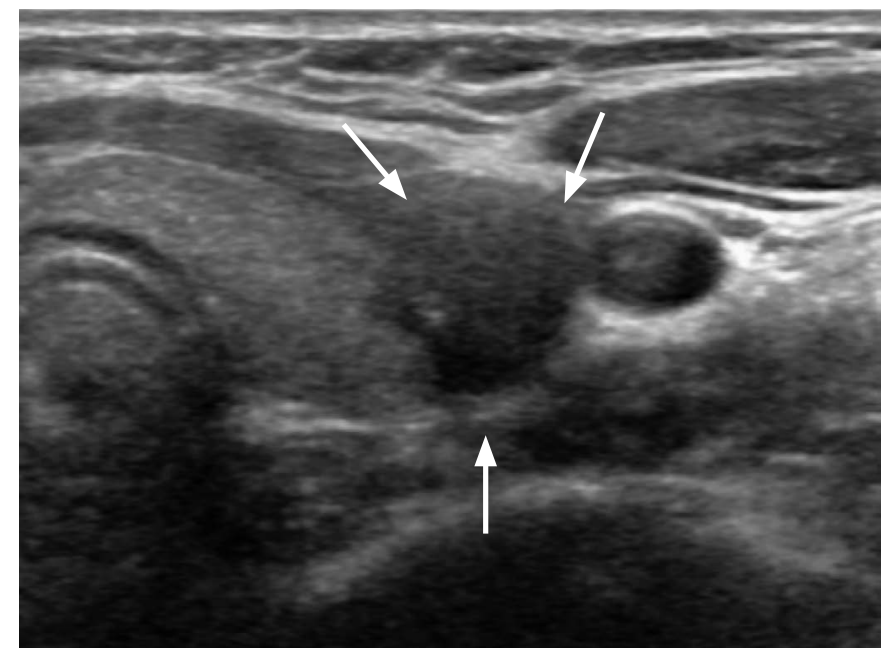

A

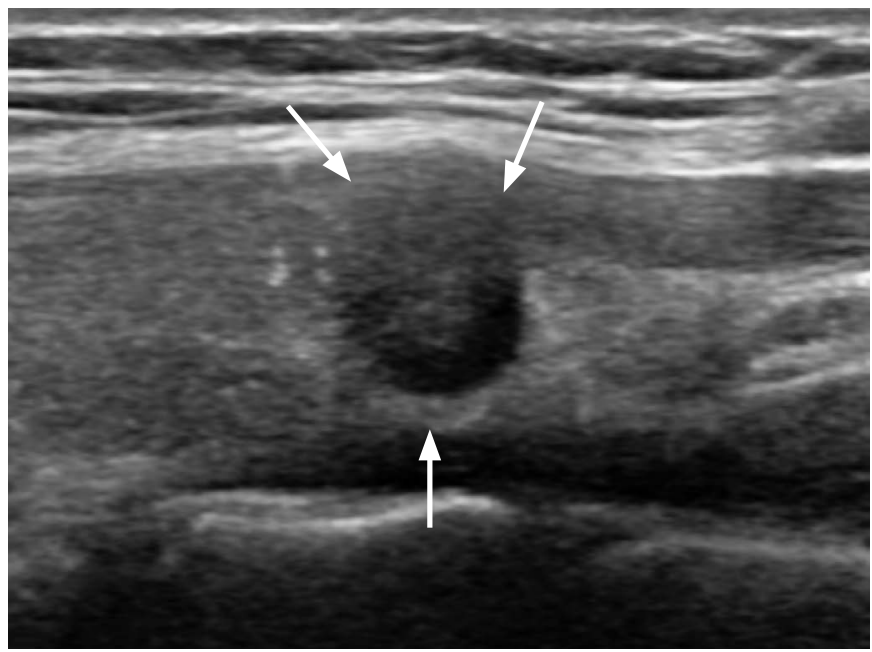

B

Fig. 3. A 24-year-old women with conventional papillary thyroid carcinoma that was diagnosed as Bethesda category VI (malignant) by fine-needle aspiration.

A, B. Ultrasonography (A, transverse; B, longitudinal view) shows a hypoechoic, irregular mass with gross invasion of the strap muscle (arrows). At surgery, central lymph node metastasis was also diagnosed.

Malignant thyroid FNA diagnoses account for $4 \%-8 \%$ of all thyroid FNAs, of which the majority are PTCs [7]. Although certain characteristic nuclear alterations help define PTC, none of them are diagnostic in isolation or in a low frequency. The minimum criteria and number of altered cells necessary for an unequivocal diagnosis are uncertain, and cases that have some features of PTC but fall short of an unequivocal diagnosis are interpreted as category III or V, depending on the quality and quantity of changes and the reviewer's level of suspicion for PTC [7]. Nodule size has been reported to be an independent factor affecting paucicellular aspirates, and therefore, smaller conventional PTCs may result in aspirates with low cellularity and be classified as category III or V [8]. In addition, larger tumors have been associated with the presence of central LNM, which may partly explain the associations of Bethesda categories with central LNM in our study [9-11].

Previous studies have focused on investigating associations between Bethesda categories and aggressive characteristics of thyroid cancer, but have varied considerably in study design and results $[2-4,12,13]$. Category VI cytology results have been consistently associated with high-risk histologic subtypes of PTC, whereas follicular variants of PTC predominate in category III cancers $[2-4,12]$. Those studies have also reported that a higher Bethesda category was associated with aggressive tumor characteristics, including a higher AJCC T and N category, lymphovascular invasion, extrathyroidal extension, and lymph node metastases. However, various histologic subtypes of PTC were included, which is reflected by the inclusion of the Bethesda category of follicular neoplasm or suspicious for a follicular neoplasm in the analyses [2-4,12]. When performing subgroup analysis according to the histologic subtype, a study reported no difference in any aggressive features according to Bethesda categories [3]. Another recent study on conventional PTC reported that the Bethesda categories were predictive of extrathyroidal extension and lymph node metastasis, although it included both minimal and extensive extrathyroidal extension and did not differentiate between central and lateral LNM [13]. Our results were largely consistent with previous studies, showing that category III and category V PTCs less frequently exhibited central LNM and were smaller than category VI PTCS.

According to the revised AJCC eighth edition TNM classification and staging system, minimal extrathyroidal extension has been eliminated from the T criteria, with only gross extrathyroidal extension influencing the $T$ category and stage groups [6]. This is primarily based on data indicating that minimal/microscopic extrathyroidal extension was not associated with survival outcomes, especially in small differentiated thyroid cancers [14-17]. In our study, category V PTCs less frequently exhibited gross extrathyroidal extension than category VI PTCs, although with borderline significance $(\mathrm{P}=0.059)$. In addition, the presence of malignantappearing US features has been reported to be associated with recurrence or poor prognostic factors in patients with conventional PTC $[18,19]$. In our study, category III PTCs less frequently showed suspicious US features than category VI PTCs. Therefore, our results suggest that Bethesda category III or V PTCs are less likely to be associated with poor prognostic factors. 
There are several limitations to our study. First, this was a retrospective study conducted at a single institution. Second, we only included patients who underwent surgery at our institution, and therefore selection bias was inevitable. Third, preoperative US and US-FNA were performed by a large number of radiologists, thus causing potential interobserver variability. However, this is an inherent part of daily clinical practice and would be present at any other institution. Fourth, Bethesda category III (AUS/FLUS) is affected by various factors, including FNA technique and specimen quality, as well as intrinsic tumor characteristics.

In conclusion, the Bethesda categories may be associated with prognostic factors in conventional PTC. Conventional PTCs classified as preoperative Bethesda category III or V may less frequently exhibit central LNM and have a smaller pathological tumor size than those with malignant cytology.

ORCID: Vivian Youngjean Park: http://orcid.org/0000-0002-5135-4058; Eun-Kyung Kim: http://orcid.org/0000-0002-3368-5013; Jin Young Kwak: http://orcid.org/00000002-6212-1495; Jung Hyun Yoon: http://orcid.org/0000-0002-2100-3513; Hee Jung Moon: http://orcid.org/0000-0002-5643-5885

\section{Conflict of Interest}

No potential conflict of interest relevant to this article was reported.

\section{References}

1. Cibas ES, Ali SZ; NCI Thyroid FNA State of the Science Conference. The Bethesda System For Reporting Thyroid Cytopathology. Am J Clin Pathol 2009;132:658-665.

2. Evranos B, Polat SB, Baser H, Ozdemir D, Kilicarslan A, Yalcin A, et al. Bethesda classification is a valuable guide for fine needle aspiration reports and highly predictive especially for diagnosing aggressive variants of papillary thyroid carcinoma. Cytopathology 2017;28:259-267.

3. Kleiman DA, Beninato T, Soni A, Shou Y, Zarnegar R, Fahey TJ 3rd. Does bethesda category predict aggressive features in malignant thyroid nodules? Ann Surg Oncol 2013;20:3484-3490.

4. VanderLaan PA, Marqusee E, Krane JF. Features associated with locoregional spread of papillary carcinoma correlate with diagnostic category in the Bethesda System for Reporting Thyroid Cytopathology. Cancer Cytopathol 2012;120:245-253.

5. Kim EK, Park CS, Chung WY, Oh KK, Kim DI, Lee JT, et al. New sonographic criteria for recommending fine-needle aspiration biopsy of nonpalpable solid nodules of the thyroid. AJR Am J Roentgenol 2002;178:687-691.

6. Tuttle RM, Morris LF, Haugen BR, Shah JP, Sosa JA, Rohren E, et al. Thyroid-differentiated and anaplastic carcinoma. In: Amin MB,
Edge SB, Greene F, Byrd D, Brookland RK, Washington MK, et al., eds. AJCC cancer staging manual. 8th ed. New York: Springer, 2017;873-890.

7. Ali SZ, Cibas ES. The Bethesda System for Reporting Thyroid Cytopathology. New York: Springer, 2010.

8. Choi YS, Hong SW, Kwak JY, Moon HJ, Kim EK. Clinical and ultrasonographic findings affecting nondiagnostic results upon the second fine needle aspiration for thyroid nodules. Ann Surg Oncol 2012;19:2304-2309.

9. Roh JL, Kim JM, Park Cl. Central lymph node metastasis of unilateral papillary thyroid carcinoma: patterns and factors predictive of nodal metastasis, morbidity, and recurrence. Ann Surg Oncol 2011;18:2245-2250.

10. Suman P, Wang CH, Abadin SS, Moo-Young TA, Prinz RA, Winchester DJ. Risk factors for central lymph node metastasis in papillary thyroid carcinoma: a National Cancer Data Base (NCDB) study. Surgery 2016;159:31-39.

11. Sun W, Lan X, Zhang H, Dong W, Wang Z, He L, et al. Risk factors for central lymph node metastasis in CNO papillary thyroid carcinoma: a systematic review and meta-analysis. PLoS One 2015;10:e0139021.

12. Liu X, Medici M, Kwong N, Angell TE, Marqusee E, Kim MI, et al. Bethesda categorization of thyroid nodule cytology and prediction of thyroid cancer type and prognosis. Thyroid 2016;26:256-261.

13. Gweon HM, Koo HR, Son EJ, Kim JA, Youk JH, Hong SW, et al. Prognostic role of the Bethesda System for conventional papillary thyroid carcinoma. Head Neck 2016;38:1509-1514.

14. Arora N, Turbendian HK, Scognamiglio T, Wagner PL, Goldsmith SJ, Zarnegar $\mathrm{R}$, et al. Extrathyroidal extension is not all equal: Implications of macroscopic versus microscopic extent in papillary thyroid carcinoma. Surgery 2008;144:942-947.

15. Leboulleux S, Rubino C, Baudin E, Caillou B, Hartl DM, Bidart JM, et al. Prognostic factors for persistent or recurrent disease of papillary thyroid carcinoma with neck lymph node metastases and/or tumor extension beyond the thyroid capsule at initial diagnosis. J Clin Endocrinol Metab 2005;90:5723-5729.

16. Radowsky JS, Howard RS, Burch HB, Stojadinovic A. Impact of degree of extrathyroidal extension of disease on papillary thyroid cancer outcome. Thyroid 2014;24:241-244.

17. Shin JH, Ha TK, Park HK, Ahn MS, Kim KH, Bae KB, et al. Implication of minimal extrathyroidal extension as a prognostic factor in papillary thyroid carcinoma. Int I Surg 2013;11:944-947.

18. Kim SY, Kwak JY, Kim EK, Yoon JH, Moon HJ. Association of preoperative US features and recurrence in patients with classic papillary thyroid carcinoma. Radiology 2015;277:574-583.

19. Nam SY, Shin JH, Han BK, Ko EY, Ko ES, Hahn SY, et al. Preoperative ultrasonographic features of papillary thyroid carcinoma predict biological behavior. J Clin Endocrinol Metab 2013;98:1476-1482. 